\title{
Reply
}

\section{Why Arguments from Expert Opinion are still Weak: A Reply to Seidel}

\section{Moti MizRAHI}

School of Arts \& Communication

Florida Institute of Technology

$150 \mathrm{~W}$. University Blvd.

USA

mmizrahi@fit.edu

\section{Introduction}

In my (2013a), I argue that "inferences from 'Expert $E$ says that $p$ ' to ' $p$ ', where the truth value of $p$ is unknown, are weak" in the sense that 'Expert $E$ says that $p$ ' does not make $p$ significantly more likely to be true or probable (Mizrahi 2013a, p. 58). My overall argument in that paper runs as follows:

(1) Arguments from expert opinion are weak unless the fact that expert $E$ says that $p$ makes it significantly more likely that $p$ is true.

(2) [As empirical evidence on expertise shows] the fact that $E$ says that $p$ does not make it significantly more likely that $p$ is true.

(3) Therefore, arguments from expert opinion are weak arguments (Mizrahi 2013a, pp. 58-59).

In other words, we should accept expert opinion as evidence only if it is significantly more likely to be true than the opinion of non-experts. Since studies on expert performance show that expert opinion is not significantly more likely to be true than novice opinion, or even significantly more likely to be true than false, we should not trust expert opinion.

Now, in a reply to my (2013a) paper, Seidel (2014, p. 196) says that he wants to "argue the contrary." As Seidel writes:

I deny that "the fact that an expert says that $p$ does not make $p$ significantly more likely to be true" (Mizrahi 2013, p. 58). I will provide 5 arguments that will show why we should not throw out the baby of epistemic trust 
on expertise with the water of reasonably doubting authorities (Seidel 2014, p. 196).

Seidel $(2014$, p. 195) says that he has "no objection to" premise (1), "since it just is a formulation of the close connection between the reliability and the epistemic trustworthiness of an epistemic source." His arguments, then, are supposed to show that premise (2) is false.

In this paper, I will argue that Seidel's objections are off the mark. That is to say, his objections fail to show that premise (2) is false. In what follows, I will address Seidel's objections and show that they are based on misinterpretations of my overall argument. Before I begin, however, a few words on rhetoric are in order. First, the "throwing the baby out with the bathwater" charge is effective only if the one to whom it is addressed thinks that the baby is worth keeping. Clearly, I do not think that "the baby of epistemic trust [in] expertise" is worth keeping. So I am not - and should not - be bothered by the "throwing the baby out with the bathwater" charge.

Second, Seidel (2014, p. 196) claims that he will argue that "We do not argue fallaciously when we argue that $p$ on the ground that an expert says that $p$," that "many inferences from 'Expert E says that $p$ ' to ' $p$ ', where the truth value of $p$ is unknown to the person making the inference, are strong arguments," and that he "will provide 5 arguments that will show why we should not throw out the baby of epistemic trust on expertise with the water of reasonably doubting authorities." But most of Seidel's "arguments" are really just objections against my argument; objections that miss their intended target, as I will show in what follows. Even if Seidel's objections were on target, they would not establish that arguments from expert opinion are indeed strong arguments, for to show that an argument against $p$ is unsuccessful does not amount to showing that $p$.

\section{Seidel's first argument}

Seidel's first objection reads like an attempt to establish trust in expertise by definition. That is to say, Seidel adopts Goldman's definition of an expert, according to which "Person $\mathrm{A}$ is an authority on subject $\mathrm{S}$ if and only if A knows more propositions in $\mathrm{S}$, or has a higher degree of knowledge of propositions in $\mathrm{S}$, than almost anybody else" (Goldman 1999, p. 268), and then says that “from Goldman's definition of expertise it follows that expert opinions in the expert's domain are far more accurate than chance" (Seidel 2014, p. 197). If this is correct, then for any per- 
son $E$ who is thought to be an expert on subject $S$, but whose assertions are only slightly more accurate than chance, "we should conclude that $E$ simply is not an expert in that domain" (Seidel 2014, p. 197).

This attempt to establish trust in expert opinion by definition, however, will not do for the following reasons. First, as Seidel himself recognizes, it amounts to "some kind of immunization strategy" (Seidel 2014, p. 198). Seidel's first argument is not only "some kind of immunization strategy" but also an instance of the dubious "no true Scotsman" maneuver. For any person $E$ that is taken to be an expert on subject matter $S$, Seidel can simply dismiss $E$ as a non-expert in case the ratio of $E$ 's true assertions to false assertions is not to Seidel's satisfaction. This strategy of making "experts should be trusted" analytic would, in effect, make expertise immune to empirical investigation, which is contrary to what Seidel $(2014$, p. 207) himself says, namely, that "checking the track-record of experts by empirical research is of major importance for assessing the reliability of experts."

Second, there is some confusion in Seidel's first objection between knowledge and opinion. Goldman's definition of an expert is stated in terms of knowledge. Knowledge is factive, i.e., if $E$ knows that $p$, then $p$ is true (Nagel 2013, p. 277). My argument, however, is about expert opinion. Unlike knowledge, opinion is not factive. That is to say, even if $E$ judges that $p$, it may still be the case that $p$ is false. Even Goldman's (1999, p. 25 ) weak sense of knowledge as true belief is factive, i.e., if $E$ truly believes that $p$, then $p$. Since opinion is not factive, and my argument is about expert opinion, a definition of expertise in terms of knowledge (in either a strong or a weak sense) does nothing to undermine my overall argument.

In another paper that aims to criticize my argument, Hinton (2015) also claims that my use of "expert opinion" is confusing. Like Seidel (2014, pp. 202-203), commenting on my characterization of an argument from expert opinion as "an argument one makes when the truth value of $p$ is unknown and the only reason to accept $p$ is the fact that an expert says so" (Mizrahi 2013a, p. 61), Hinton (2015, p. 541) asks, "unknown to whom?"

This question, however, is misguided. As mentioned above, knowledge is factive. So, if an expert knows that $p$, then $p$. And if a novice who is appealing to expertise knows that $p$, then $p$. In both cases, then, an argument from expert opinion would be redundant, since $p$ is already known to be true. Opinion, on the other hand, is not factive. Even if an expert judges 
that $p, p$ could still be false. And even if a novice judges that $p$, it might not be the case that $p$. For this reason, I talk about expert opinion rather than expert knowledge. Contrary to what Seidel and Hinton claim, this use of 'opinion', as something that falls short of knowledge, is not idiosyncratic (pace Hinton 2015, p. 545). In fact, it goes all the way back to Plato's dialogues, in particular, the ones in which Socrates discusses the difference between knowledge (episteme) and mere opinion (doxa) (Wolenski 2004, p. 6). Moreover, this is also the way 'opinion' is typically used in argumentation theory (Wohlrapp 2014, pp. $\mathrm{xx}-\mathrm{xxi}$ ).

To put it another way, if arguments from expertise were arguments from expert knowledge rather than expert opinion or judgment, then such arguments would be deductively valid. Since from

\section{$E$ knows that $p$}

it necessarily follows that $p$, given that knowledge is factive. Both Seidel (2014, p. 194) and Hinton (2015, p. 542), however, agree that arguments from expertise are not supposed to be deductively valid. So they must accept that arguments from expertise are not arguments from what experts know (otherwise, they would be deductive) but rather from what experts believe or judge to be the case; in other words, from expert opinion. The question, then, is whether arguments from expert opinion are good ampliative arguments, i.e., whether we can gain new knowledge by arguing on the basis of expert opinion. My argument in (2013a) shows that the answer is "probably not."

Finally, Seidel's first objection is based on the erroneous assumption that my FBI example is supposed to "sustain [my] thesis" (Seidel 2014, p. 199), which then allows Seidel to apply his immunization strategy and argue that the FBI is not an authority of expertise on counterfeiting (even though counterfeiting is a federal crime in the United States, and thus under the jurisdiction of the FBI, which investigates so-called "white collar" crimes, such as fraud ${ }^{1}$ ). As I (2013a, p. 63) clearly state, however, my examples do not play an evidential role in my overall argument. That is to say, they are not meant to "sustain my thesis" (by "sustain" I take it that Seidel means "support") but rather to illustrate it. As can be seen from the way I sum up my overall argument (quoted in Section 1), the FBI example does not figure in this argument at all. The support for premise

\footnotetext{
${ }^{1}$ See http://www.fbi.gov/about-us/investigate/white_collar/ipr/ipr.
} 
(2), which is the premise that Seidel seeks to challenge, comes from the results of experimental studies, not a few examples.

For these reasons, Seidel's first argument fails to show that premise (2) of my overall argument is false. Seidel's first argument renders expertise immune to empirical investigation, contrary to what Seidel (2014, p. 207) himself claims, confounds knowledge and opinion, and erroneously attributes two examples discussed in my (2013a) paper an evidential role that they do not play. I will now proceed to examine Seidel's second argument.

\section{Seidel's second argument}

Seidel's second objection, which is supposed to show that premise (2) of my overall argument is false, runs as follows:

Since some of the empirical material cited by Mizrahi concerns predictions and since experts do not just make predictions, it is fallacious to think that this material supports the conclusions that arguments from expert opinion are weak (Seidel 2014, p. 203).

To Seidel (2014, p. 204), it "seems [that Mizrahi] forget about other kinds of knowledge from expertise."

There are several problems with Seidel's second argument. First, it is true that some of the studies I cite in support of the claim that expert opinion is unreliable are about experts making predictions. But not all of them involve experts making predictions. Some involve experts making decisions. Others involve experts giving diagnoses. Still others involve experts generally failing to outperform non-experts on a variety of tasks.

Second, Seidel simply asserts without argument that there are some expert assertions that amount to knowledge. He invokes the notion of scientific progress and claims that trust in expertise is necessary for scientific progress. Even if that is true, and Seidel does not provide reasons to think that it is, there is some confusion here between epistemic trust in expertise, i.e., trusting that $p$ is true because $E$ judges that $p$ is true, and what we might call professional trust, i.e., trusting that $E$ is a professional. For example, I may trust my physician insofar as she is a professional who knows what she is doing (e.g., she knows how to perform physical examinations and make clinical decisions) but I may still mistrust her diagnosis in a particular case and seek a second opinion. In the scientific context, the latter kind of trust means that $E$ is to be trusted to correctly follow procedures 
of scientific observation and protocols of scientific experimentation; in other words, that $E$ is a professional scientist. As far as arguments from expert opinion are concerned, however, the relevant kind of trust is epistemic trust in expertise (i.e., trusting that $p$ is true because $E$ judges that $p$ is true), not professional trust (i.e., trusting that $E$ is a professional). ${ }^{2}$ Seidel seems to acknowledge this point when he approvingly quotes me (Mizrahi 2013a, p. 67):

Surely, no scientist should establish conclusions just by pointing out that he says so but-as Mizrahi correctly notes-by "appeal to observations and experiments" (Mizrahi 2013, p. 67) (Seidel 2014, p. 204).

Even if there is a division of labor in the sciences, and even if this sort of division of labor makes scientific progress possible, ${ }^{3}$ as Seidel (2014, p. 204) asserts without argument, my overall argument still stands because it is about epistemic trust in expertise (i.e., accepting what an expert says as true just because she says so), not professional trust (i.e., trusting that a professional knows what she is doing). ${ }^{4}$ As I (Mizrahi 2013a, p. 59) point out, a parallel distinction is often made in argumentation theory between administrative (or practical) authority and cognitive (or epistemic) authority (see, e.g., Walton 1997, pp. 77-78, Goodwin 1998, pp. 268-269, and Hansen 2006, pp. 320-321).

For these reasons, Seidel's second argument fails to show that premise (2) of my overall argument is false. Seidel's second argument ignores the fact that the experimental studies I cite in support of premise (2) involve experts engaging in cognitive tasks other than making predictions, presupposes without additional argument that some expert opinion amounts to

\footnotetext{
${ }^{2}$ Cf. Wray (2007, pp. 88-91) on scientists making implicit and explicit judgments about other scientists' competence.

${ }^{3}$ In that respect, it is worth noting that in the literature on science and values, philosophers of science distinguish between epistemic values, i.e., values that are conducive to truth or knowledge, and non-epistemic values, i.e., values that are ideological or ethical (Dorato 2004, pp. 52-77).

${ }^{4}$ Incidentally, I published on the question of scientific progress (see Mizrahi $2013 \mathrm{~b}$ and 2014). Because Kuhn is a skeptic about theoretical truth, he construes progress in terms of a notion that he takes to be neutral with respect to theoretical truth and knowledge, namely, puzzle-solutions. For this reason, Seidel's remarks about Kuhn's notion of scientific progress in footnote 17 (Seidel 2014, p. 204) are not only inaccurate but also of no use to his case against my overall argument, since for Kuhn progress is neither a matter of accumulating truths (or knowledge) nor a matter of following rules, including rules of inference, but rather a matter of similarities between puzzle-solutions (Mizrahi 2014, pp. 153-156).
} 
knowledge, and confounds epistemic trust with professional trust. I will now proceed to examine Seidel's third argument.

\section{Seidel's third argument}

Seidel's $(2014$, p. 208) third objection is to claim that "the empirical evidence cited by Mizrahi is [...] no reason to conclude quite generally that experts are only slightly more accurate than chance" because it "concern[s] expert-judgment in fields that probably are special with respect to the reliability of their results and predictions" (Seidel 2014, p. 205). Seidel does not say what makes these fields (namely, economics, public policy, journalism, medicine, and psychology, among others) "special." Seidel $(2014$, p. 205) says that articulating the ways in which these fields are different from "other disciplines like, e.g., physics or chemistry" is beyond the scope of his paper. The only thing Seidel offers by way of support for this assertion is the following quotation: "economic predictions are notoriously unreliable" (Sen 1986, p. 3).

So, Seidel objects to my overall argument from expert performance to the effect that appeals to expert opinion are weak arguments by appealing to the authority of expertise. If my argument that arguments from expert opinion are weak is sound, then Seidel's appeal to Sen's expertise is a weak argument. Indeed, it is not even clear that Sen has the relevant expertise on the subject matter at hand. Sen's assertion that "economic predictions are notoriously unreliable" is not an economic claim but a claim about economics. In other words, it is a meta-economic claim, whose proper domain is perhaps the philosophy of science (or perhaps more specifically, the philosophy of economics). If Sen is not a philosopher of science, then appealing to him as an expert on the reliability of economic predictions is fallacious, even by Seidel's own lights.

Seidel's attempt to undermine the empirical evidence on expert performance by distinguishing between fields that admit of expertise and "special" fields that do not is another application of the immunization strategy from his first argument. That is to say, the first premise of my overall argument, which Seidel (2014, p. 195) accepts, is that appeals to expert opinion are strong only if the fact that $p$ is the opinion of an expert makes it significantly more likely that $p$ is true. Since, as a matter of fact, that is not the case, as experimental studies on expert performance show, it follows that appeals to expert opinion are weak arguments. Seidel accepts the first premise, and so, to avoid my 
conclusion, he claims instead that the experts studied in the studies I cite are not really experts. This is another instance of the dubious "no true Scotsman" move: for any domain $D$ in which the opinions of practitioners are only slightly more accurate than chance, Seidel can simply dismiss $D$ as a "special" domain that does not admit of expertise. Again, this strategy would, in effect, make expertise immune to empirical investigation, which is a consequence that Seidel (2014, p. 207) himself would not accept.

Seidel (2014, p. 206) claims that, if I want to use experimental studies about expert performance in some domains as evidence about expert performance in all domains, I must rule out "the possibility that the unreliability of experts in these domains stems from specific features of these domains." In other words, the burden of proof is on me to show that the experts in those fields that Seidel deems "special" are just like experts in other fields. Disagreements about who has the burden of proof are notoriously difficult to settle. Contrary to Seidel, I could argue that the burden of proof actually lies with Seidel. After all, it is Seidel who wants to draw distinctions between experts. If so, then Seidel has to draw these distinctions in a principled way and show why we should distinguish between experts in the ways he proposes. In that respect, it is important to note that argumentation theorists make no such distinctions as far as arguments from expert opinion are concerned. For instance, the $E$ in Walton's scheme for argument from expert opinion is supposed to be any expert whatsoever, not just some experts or experts in "special" domains (Walton et al 2008, p. 310).

For these reasons, Seidel's third argument fails to show that premise (2) of my overall argument is false. Like his first argument, Seidel's third argument is an instance of the "no true Scotsman" immunization maneuver, and thereby renders expertise immune to empirical investigation. Moreover, Seidel's third argument amounts to an appeal to expert opinion, which is not only question-begging but also fallacious, even by Seidel's own lights, and assumes without further argument that some fields are "special" and do not admit of expertise. I will now proceed to examine Seidel's fourth argument.

\section{Seidel's fourth argument}

Seidel's fourth objection is to claim that the fact that "research on expertise has shown that in some fields most of the results published in top journals are rejected after a few years" does not 
"sustain the claim that experts in these fields are only slightly more accurate than chance" (Seidel 2014, p. 210). If by "sustain" Seidel means that the fact that results published in economics and medical journals are subsequently considered incorrect does not make it more likely or probable that the opinions of experts in these domains are only slightly more accurate than chance, then I think that Seidel is right about that. Results that are published in professional journals are usually not backed up by appeals to expert opinion. Rather, they are usually backed up by evidence collected from observations, experiments, surveys, analyses, and the like. As far as scientific publications are concerned,

scientists themselves rarely, if ever, establish conclusions by appealing to expertise. Instead, scientists usually appeal to observations and experiments, among other things, not to expertise (Mizrahi 2013a, p. 74).

Accordingly, the fact that "approximately two-thirds of the findings published in top medical journals are rejected after a few years" does not support premise (2) of my overall argument because premise (2) is about expert opinion, whereas findings published in medical journals are typically not mere opinions.

So what does support premise (2)? The empirical evidence that supports premise (2) comes from experimental studies on expert performance. These studies show that "expert opinions are usually no more accurate than guessing (i.e., roughly 50\%)" (Mizrahi 2013a, p. 65). For example, in Part I of his (1994), which I cite as evidence for premise (2), Dawes discusses several studies which show that, under conditions of uncertainty (i.e., when the truth value of an assertion is unknown), experts fail to perform better than non-experts. For example, Dawes discusses a study by Faust et al (1988) which shows that clinical neuropsychologists failed to "detect young adolescents who were faking brain damage on standard intellectual tests after being given virtually no instructions about how to do it other than 'to be convincing"" (Dawes 1994, p. 91). To these studies in support of premise (2), we can add the following:

Johnson (1988) shows that experts fail to perform better than non-experts in evaluating candidates for internships in medical fields.

Hinds (1999) shows that experts were significantly worse than non-experts in predicting performance of novices in tasks such as assembling a LEGO set. 
More recent studies can be found in Ericsson et al (2006). ${ }^{5}$ These studies, and others showing similar results, support premise (2).

For these reasons, Seidel's fourth argument fails to show that premise (2) of my overall argument is false. Seidel's fourth argument fails to engage with the empirical evidence that actually supports premise (2), namely, evidence from experimental studies suggesting that experts fail to outperform novices on a variety of tasks and are generally not significantly more likely to be right than wrong. I will now proceed to examine Seidel's fifth argument.

\section{Seidel's fifth argument}

Seidel (2014, p. 213) argues that it "is virtually impossible to argue that arguments from expert opinion are weak because such arguments implicitly assume that arguments from expert opinion are strong." In other words, Seidel accuses me of using "evidence gained assuming the reliability of an epistemic method [namely, appealing to expert opinion] in order to sustain the claim that this epistemic method is not reliable" (Seidel 2014, p. 213).

As evidence for the claim that I am (implicitly) assuming the reliability of appeals to expert opinion, Seidel offers the following quotation: "Luckily, I don't have to [conduct experiments on expert performance]. Others have done the hard work already" (Mizrahi (2013a, p. 76). And then writes: "Therefore, Mizrahi is relying on the expertise of others in conducting empirical studies on expertise in order to come to this claim that there is empirical evidence for the conclusion that arguments from expert opinion are weak arguments" (Seidel 2014, p. 213; emphasis added).

But this is a non sequitur. From the fact that I cite experimental studies in support of a claim it does not follow that I accept the results of these studies just because they are reported by "experts." In fact, I say that immediately after the aforementioned passage quoted by Seidel:

I may even need those who have conducted the studies to explain the results to me. But that doesn't mean that I am appealing to the expertise of those who have conducted

\footnotetext{
${ }^{5}$ For a recent discussion of these, and similar studies, with respect to the question of philosophical expertise, see Buckwalter (2014).
} 
the studies. Explanations and arguments are not the same thing (Mizrahi 2013a, p. 76; emphasis in original).

In other words, I do not accept $p$ because $p$ is asserted by $E$ or because $E$ judges that $p$ is the case. Rather, I accept $p$ because $p$ is a result that was arrived at by experimentation.

Seidel might retort that I need to assume the reliability of appeals to expert opinion in order to appeal to experimental results. But that is simply not true. For there is a clear difference between the inference from 'Expert $E$ judges that $p$ ' to ' $p$ ' (where $p$ is an opinion or judgment whose truth value is unknown and the only reason to accept $p$ is that $E$ asserts it) and the inference from 'Experiment $X$ yields the result that $r$ ' to ' $r$ '. The former is an appeal to the judgment of a person who is considered an authority of expertise on the subject matter in question, whereas the latter is an appeal to a procedure that it taken to be reliable in producing results of a particular kind. Indeed, I also cite empirical evidence suggesting that decision procedures are more reliable than expert judgments (Mizrahi 2014, pp. 6466). ${ }^{6}$

This misinterpretation of my overall argument, I submit, is the result of several confusions. First, Seidel mistakenly takes the two examples discussed in Section 2 of my (2013a) as playing an evidential, as opposed to an illustrative, role in my overall argument. In particular, Seidel claims that I argue from the premise that "Experts different from Fleischmann and Pons say that they could not replicate the results by Fleischmann and Pons" (Seidel 2014, p. 216) to the conclusion that "The results by Fleischmann and Pons could not be replicated by other experts" (Seidel 2014, p. 216). But this is not my argument. In fact, I explicitly say that "to support the claim that arguments from expert opinion are weak arguments, we need more than a few counterexamples" (Mizrahi 2013a, p. 63). Accordingly, the FBI and cold fusion examples play no evidential role in my overall argument. Premise (1), which Seidel accepts, is an instance of the principle that an unreliable epistemic source is not trustworthy. My argument for premise (2) is an argument from empirical evidence. That is to say:

Experiments show that the opinions of experts are not significantly more likely to be true than the opinions of novices.

\footnotetext{
${ }^{6}$ See also Dawes (1994, p. 93). Seidel writes that he "will be silent about comparing the reliability of expert opinions to the reliability of decision procedures" (Seidel 2014, p. 195; footnote 5).
} 
Therefore, whether an opinion is that of an expert or a novice has no significant effect on whether or not it is true.

A few examples, of course, cannot establish a claim about statistical significance; only certain procedures (i.e., experimental studies) can do that.

Second, interpreting the FBI and cold fusion examples as playing an evidential role in my overall argument is not only erroneous but also uncharitable. Given that I characterize arguments from expert opinion as "arguments that cite the mere fact that an expert says that $p$-as opposed to the fact that that $p$ is common knowledge in a particular field or that the expert in question is reporting that most experts in the field say that $p$-as the only reason to accept $p$ " (Mizrahi 2013a, p. 61; emphasis in original), and emphasize that such arguments are made "when the truth value of $p$ is unknown and the only reason to accept $p$ is the fact that an expert says so" (Mizrahi 2013a, p. 61), a more charitable interpretation of the role that these examples play in my (2013a) paper is the following. These examples are meant to illustrate instances in which the only reason to accept $p$ is the fact that an expert says so. Accordingly, the cold fusion example is supposed to illustrate a situation in which the only reason to accept the claim that nuclear fusion can occur at room temperature is the fact that Fleischmann and Pons say so, since their results could not be replicated. It does not matter who tried to replicate their results. The fact that the results could not be replicated means that one cannot appeal to the experimental results directly but rather must take Fleischmann and Pons' word for it. Similarly, the FBI example is supposed to illustrate a situation in which the only reason to accept the claim that US businesses lose \$200-250 billion to counterfeiting every year is the fact that the FBI says so, since this estimate could not be corroborated in any other way. The fact that the estimate could not be corroborated in other ways means that one cannot appeal to other sources but rather must take the FBI's word for it. (Of course, if I am right, then one should not take either Fleischmann and Pons' or the FBI's word for it.)

Even if the cold fusion example did play an evidential role in my overall argument, it would still be false that I need to assume that replication must be done by experts. For it does not matter "who conducted the empirical studies" (Mizrahi 2013a, p. 63) or replications of experimental studies. To think otherwise is to fail to distinguish between cognitive authority and administrative authority, between epistemic trust and professional trust, 
and between judgments and procedures. To support premise (2), all that I need to assume is that the scientists who conducted the studies on expert performance are professionals, i.e., they can be trusted to follow procedures (e.g., protocols of randomization, blinding, and the like), not that they are experts whose judgments are to be believed or accepted. In other words, I accept the results of experimental studies on expert performance because they are the results of properly conducted experiments, not because they are asserted or reported by experts.

\section{Conclusion}

To sum up, Seidel's objections fail to undermine premise (2) of my overall argument because they are based on a misinterpretation of the evidential role that the experimental studies on expert performance play in my argument. Seidel misinterprets my argument because he fails to distinguish between administrative (or practical) authority and cognitive (or epistemic) authority, between epistemic trust and professional trust, and between judgments and procedures, and he mistakenly thinks that the cold fusion and FBI examples play an evidential role in my (2013a). Even if Seidel's objections were not off the mark, as I have argued, they would still not show that arguments from expert opinion are strong arguments, for showing that my argument for the claim that arguments from expert opinion are weak fails does not amount to support for the claim that arguments from expert opinion are strong.

For this reasons, I submit that the main challenge raised by the overall argument I put forth in my (2013a) still stands. The challenge is how to justify the assumption that an expert's judgment that $p$ is (defeasible) evidence for $p$. This unwarranted assumption is implicit in any argumentation scheme for arguments from expert opinion, no matter how many premises that argumentation scheme contains or how many critical questions are added to it (Mizrahi 2013a, pp. 67-72). ${ }^{7}$

\section{Acknowledgments}

I am grateful to Andrew Aberdein for comments on an earlier draft of this paper.

\footnotetext{
${ }^{7}$ See Mizrahi (forthcoming).
} 


\section{References}

Buckwalter, W. (2014). Intuition Fail: Philosophical Activity and the Limits of Expertise. Philosophy and Phenomenological Research. DOI: 10.1111/phpr.12147.

Dawes, R. M. (1994). House of Cards: Psychology and Psychotherapy Built on Myth. New York: The Free Press.

Dorato, M. (2004). Epistemic and Nonepistemic Values in Science. In P. Machamer and G. Wolters (eds.), Science, Values, and Objectivity (pp. 52-77). Pittsburgh, PA: University of Pittsburgh Press.

Faust, D., Hart, K. J., and Guilmette, T. J. (1988). Pediatric Malingering: The Capacity of Children to Fake Believable Deficits on Neuropsychological Testing. Journal of Consulting and Clinical Psychology 56, 578-582.

Goldman, A. I. (1999). Knowledge in a Social World. New York: Oxford University Press.

Goodwin, J. (1998). Forms of Authority and the Real Ad Verecundiam. Argumentation 12, 267-280.

Hansen, V. H. (2006). Whatley on Arguments involving Authority. Informal Logic 26, 319-340.

Hinds, P. J. (1999). The Curse of Expertise: The Effects of Expertise and Debiasing Methods on Prediction of Novice Performance. Journal of Experimental Psychology: Applied 5, 205-221.

Hinton, M. (2015). Mizrahi and Seidel: Experts in Confusion. Informal Logic 35, 539-554.

Johnson, E. J. (1988). Expertise and Decision under Uncertainty: Performance and Process. In Chi, M. T. H., Glaser, R., \& Farr, M. J. (Eds.), The Nature of Expertise (pp. 209-228). Hillsdale, NJ: Erlbaum.

Mizrahi, M. (2013a). Why Arguments from Expert Opinion are Weak Arguments. Informal Logic 33, 57-79.

Mizrahi, M. (2013b). What is Scientific Progress? Lessons from Scientific Practice. Journal for General Philosophy of Science 44, 375-390.

Mizrahi, M. and Buckwalter, W. (2014) The Role of Justification in the Ordinary Concept of Scientific Progress. Journal for General Philosophy of Science 45, 151-166.

Mizrahi, M. (forthcoming). Arguments from Expert Opinion and Persistent Bias. Argumentation, Objectivity, and Bias: Proceedings of the $11^{\text {th }}$ International Conference of the Ontario Society for the Study of Argumentation (OSSA), May 18-21, 2016. 
Nagel, J. (2013). Knowledge as a Mental State. In T. Szabó Gendler and J. Hawthorne (eds.), Oxford Studies in Epistemology Vol. 4 (pp. 273-308). Oxford: Oxford University Press.

Seidel, M. (2014). Throwing the Baby Out with the Water: From Reasonably Scrutinizing Authorities to Rampant Scepticism about Expertise. Informal Logic 34, 192-218.

Sen, A. K. (1986). Prediction and Economic Theory. Proceedings of the Royal Society of London A 407, 3-23.

Walton, D. N. (1997). Appeal to Expert Opinion: Arguments from Authority. University Park, PA: Pennsylvania State University Press.

Walton, D. N., Reed, C., and Macagno, F. (2008). Argumentation Schemes. Cambridge: Cambridge University Press.

Wohlrapp, H. R. (2014). The Concept of Argument: A Philosophical Foundation. T. Personn and M. Weh (trans.). Dordrecht: Springer.

Wolenski, J. (2004). The History of Epistemology. In I. Niiniluoto, M. Sintonen, and J. Wolenski (eds.), Handbook of Epistemology (pp. 3-54). Dordrecht: Kluwer Academic Publishers.

Wray, K. B. (2007). Evaluating Scientists: Examining the Effects of Sexism and Nepotism. In H. Kincaid, J. Dupré, and A. Wylie (eds.), Value-Free Science? Ideals and Illusions (pp. 87-106). New York: Oxford University Press. 